unate. We dcn't know fully the circumstances of the attempted capture, nor the cause of the bird's death, but this incident is greatly to be regretted since it will be pointed to eagerly by the critics of a management scheme.

For those people watching for Whooping Cranes in migration this fall, Mr. Bard gave the following pointers. Examine carefully the areas where Sandhills congregate for migration. During the critical first week or two in October, when Sandhills are migrating, keep binoculars handy and scan each migrating flock. Check and double check to be sure that any bird seen with Sandhills which seems white when reflecting light is still white when back-lighted. If Whooping Cranes are seen feeding in the stubble (and therefore likely to remain for two or three days), telephone report to the museum; otherwise, submit reports by letter. Finally, remember the Whooping Cranes are not likely to be seen in large flocks-groups are not usually larger than five or six.

\title{
Observations at a Garter Snake Hibernaculum
}

\author{
By ROBERT W. NERO, Saskatchewan Museum of Natural History
}

Occasional reports of large concentrations of snakes have been received by the Museum for many years but until now none of these sites has been examined. On April 29, 1957, Mr. Tom Gentles of Regina gave us a detailed description of a "snake hill" found by him on the previous day near Estevan, Saskatchewan: Since a trip to this vicinity had already been scheduled for other purposes, we were able to verify this report on the following day. Roy G. Young and LeRoy A. Faibish of the Department of Natural Resources, Fred G. Bard, and the author made up the party which visited the site. We arrived at the spot described by Mr. Gentles on the second terrace on the south side of the Souris River valley a few miles southeast of Estevan, at noon on a hot bright day. It was at once clear that our informant had not been exaggerating in his description of a mutitude of snakes. In an hour and a half we saw at least 500 snakes, all of which were apparently Redsided Garter Snakes (Thamnophis sirtalis parietalis).

A small gulley about 100 feet long, 20 feet wide at the widest part and about 10 feet deep was the centre of attraction. This gulley was evidently the result of a cave-in over a burnt-out coal mine shaft. It was fairly open for the most part with a verticle exposure of burned or rather baked shale along the west slope at the upper end. This exposure appeared to be the actual den-site, the many vertical and horizontal crevices evidently offering ideal conditions for a hibernaculum. (Fig. 1) Snakes were numerous on the surface above the den-site and in the bushy area at the base of the gulley as well as in the actual gulley but only a few were found in other nearby pits and gullies. Abcut 120 snakes were first located beneath a clump of snowberry (Symphoricarpos sp.). Many were on the ground in the shade of these bushes but others rested in the tops of the brush and these moved quite rapidly along on the branches: At two places beneath the bushes snakes were found in writhing masses of 30 or more each. It was noticed that when the snakes were disturbed they moved rapidly away but tended to return to their origina locations. In places beneath the snowberry the leaves and twig formed windrows around bare spots evidently the result of the sweepin: movement of many snakes. This wa particularly evident on the mor sloping portions of the area.

On the ledge beneath the "cliff" cluster of about 60 snakes was foun (Fig. 2). During the 20 to 30 minute of observation of this group other moved out from the cracks unt about twice as many were presen In the bottom of the gulley at thi point another mass was found con taining at least 30 individuals.

soon became apparent that the mem bers of each of the masses which w had under observation tended to sta together as they moved about follow ing disturbance. Individuals whic became separated quickly returned the main mass. Furthermore, each masses contained one large membe 
vidently a male, and it was this arger snake which seemed to hold he attention of the group of snakes. Most of the snakes were about two eet long, but one of the "leaders" vas approximately three feet long. the smallest snake found was a litle less than 12 inches in length). As he larger snake in a group moved, ther members followed rapidly, oiling about and clinging to the arger one. At times the larger snake ppeared to attempt to free itself rom the impending group by jerking and twisting and in cne case a "leader" did move away from the est of the group. This social beravior (whether it was sexual or ggressive. was not determined) eemed to be the basis for the large nasses. At one moment a portion of the mass on the ledge slithered lownward; here again, several snakes clung closely to the larger one by vrapping themselves about its body (Fig. 3. 4).

On the slope of the hill adjacent to nd above the shale ledge a great many snakes were seen with heads extending out of "gopher" holes; as many as 30 were counted in one hole. These quickly withdrew upon disturoance, seeming to go down into the recesses of the shale bed. Judging by the matted grass in this area a good deal of activity had taken place here. Similarly, many holes along the walls of the gulley and especially worn paths or slides leading to these holes indicated a considerable movement of snakes. The whole situation sugested that far more snakes were involved than we were able to count

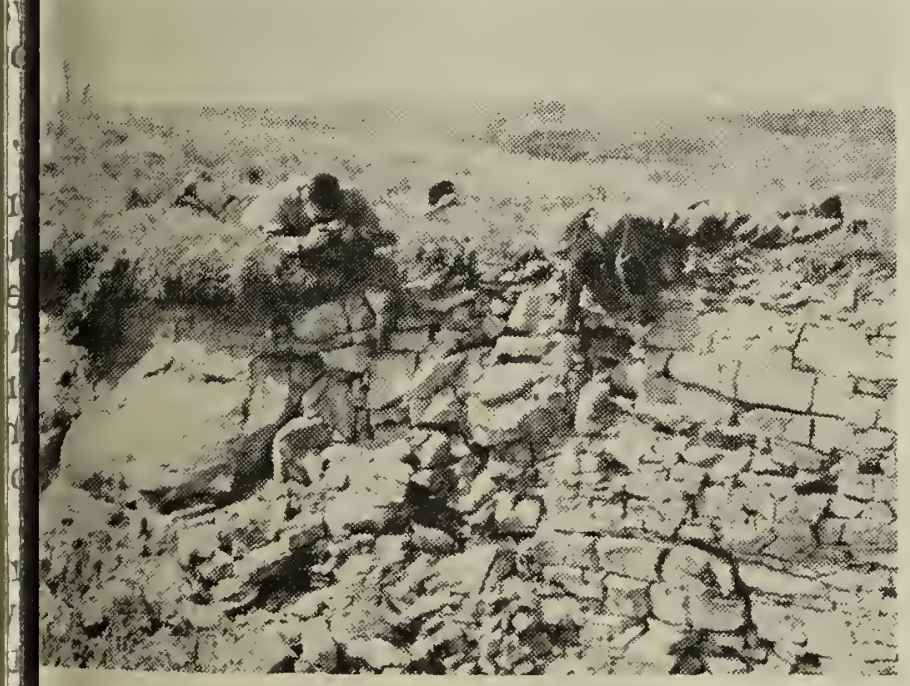

Photo by F. G. Bard

Fig. 1. Baked shale den-site. Note mass of snakes in the lower centre of photo outside main entrance of densite. and that many had already dispersed or were still underground. Evidently the baked shale ledge with its many cracks and crevices has provided ideal winter hibernation quarters for this species of snake. According to a brief communication from $\mathrm{Mr}$. E. Jenish, owner of the property, snakes have been seen in large numbers at this site in the spring and fall for a number of years.

Snakes and other reptiles commonly come together in large groups during hibernation and this is presumably the explanation for most of the reported "snake hills". Mr. Stuart Criddle of Treesbank, Manitoba, has described in detail observations of snakes found in an anthill (1937. Snakes from an ant hill. Copeia, 2:142). A total of 257 were found by him from one to three feet deep in the chambers of a large ant hill during September and October. Eight of these were Plains Garter Snakes, 101 were Red-bellied Snakes and 148 were smooth Green Snakes! Snakes have also been found hibernating in an ant hill in Michigan as well as in a crayfish burrow and a meadow vole tunnel, according to .Charles C. Carpenter (1953. A study of hibernacula and hibernating associations of snakes and amphibians in Michigan. Ecology, 34:74-80.).

Dr. E. B. S. Logier has indicated that relatively little is known of the hibernating habits of reptiles. Here again local naturalists have an opportunity to contribute to our knowledge of the behavior of our fauna. Reports of den-sites need to be checked and a rewarding study awaits anyone who undertakes to

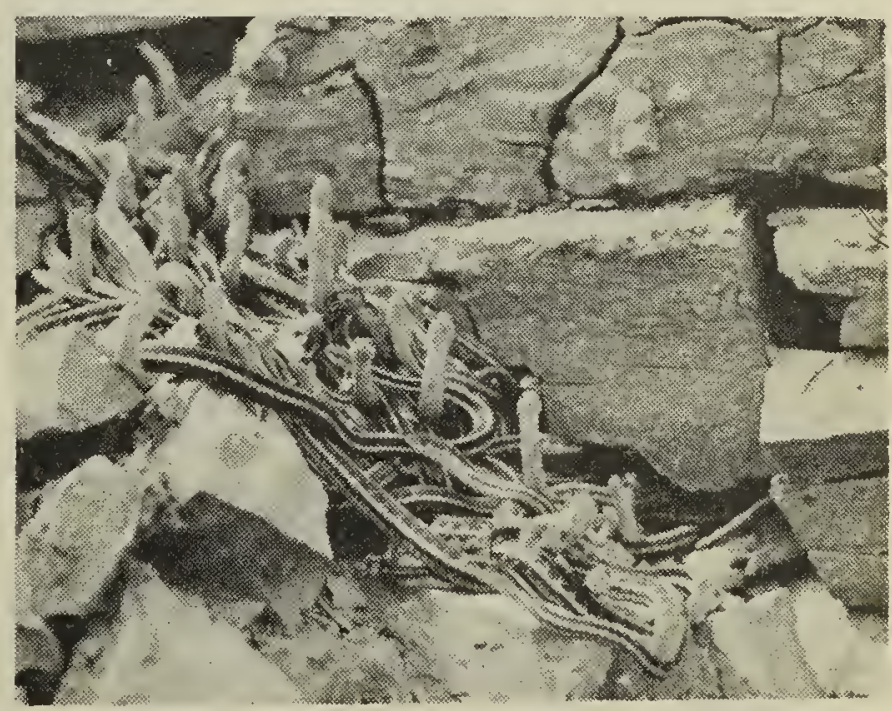

Photo by F. G. Band

Fig. 2. Close-up of portion of mass of snakes in fig.1. At least 50 heads show. 
understand the full meaning of the behavior which we observed in our short visit. Undoubtedly, the snakes at the Estevan site represent the population of a wide area, but only by locating marked individuals can we obtain any idea of the distance which these snakes move. Studies of social and individual behavior at the den-site should be especially interesting. It would be of considerable value to have a record of daily ap- pearance and withdrawal, reaction to changes in daily weather, etc, during the period of emergence in the spring and prior to the final withdrawal in the fall.

EDITOR'S NOTE: Colored motion pictures of the snakes at the Estevan site were taken by Fred G. Bard and will provide one of the exciting events on the programme of the annual meeting of the S. N. H. S. at the Museum in October.

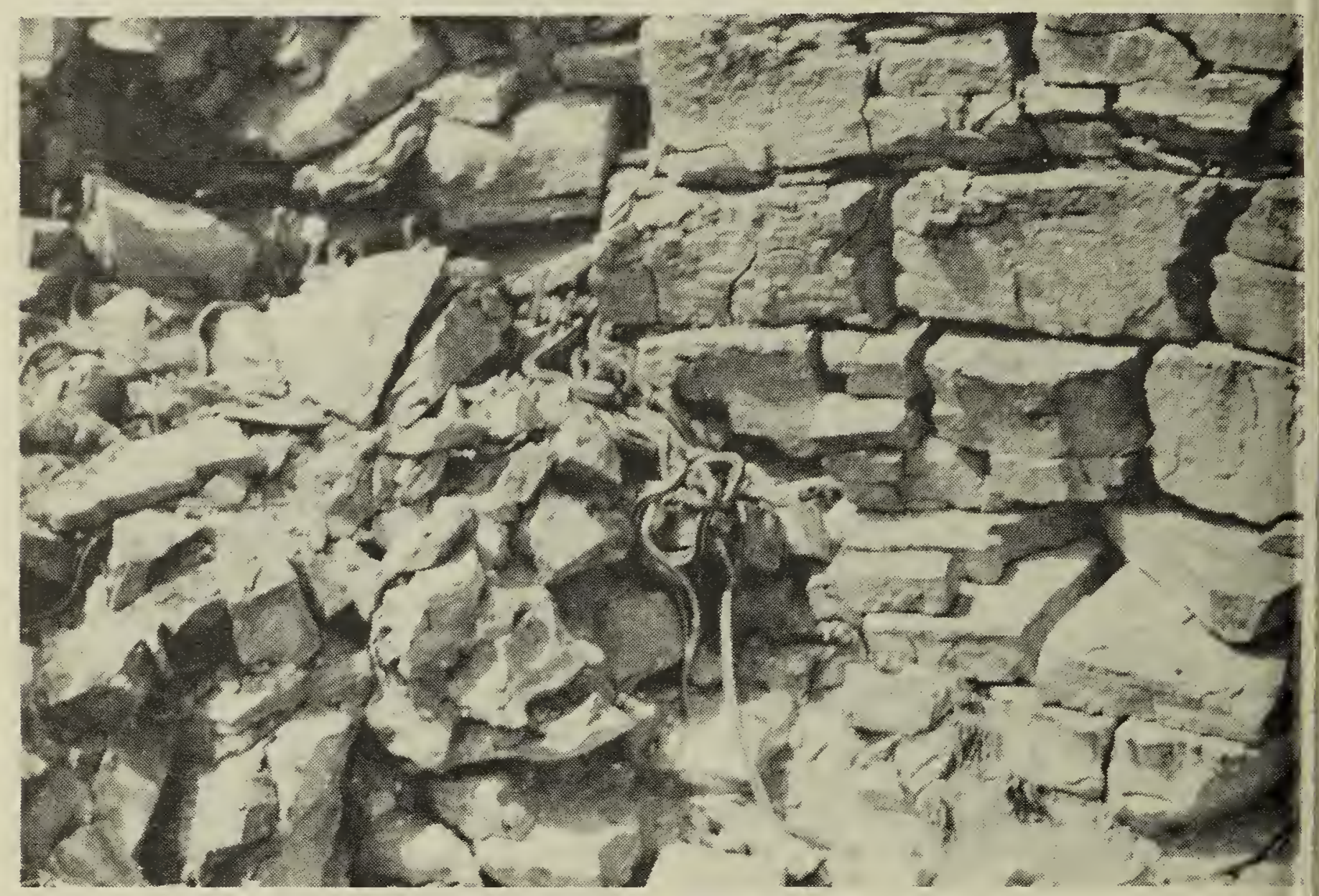

Photo by F. G. Bat

Fig. 3. Portion of the main group of snakes slithering downward followin movement of large snake.

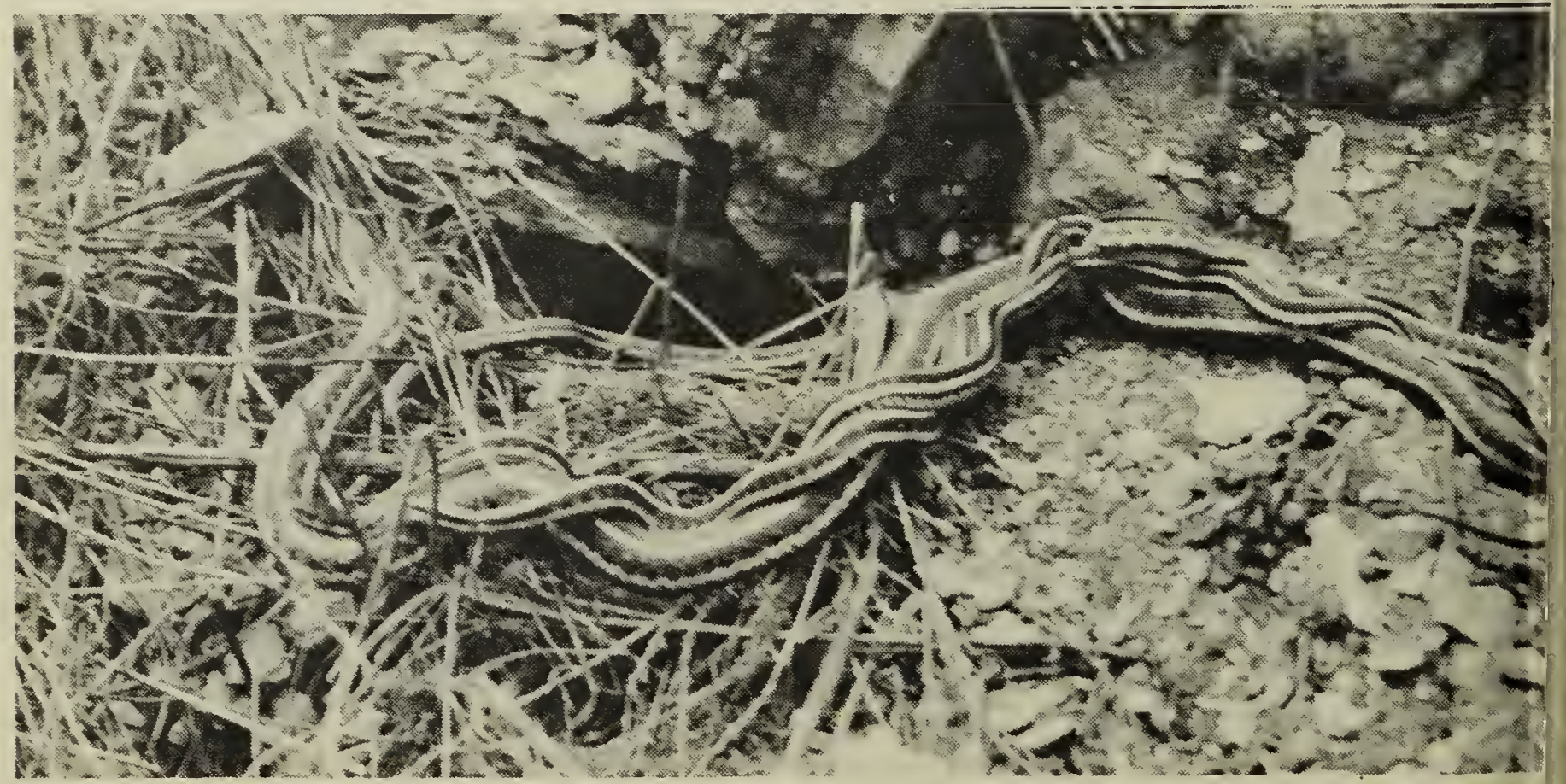

Fig. 4. One large snake moving away with smaller individuals twinin about its body. 